\title{
A study based on records taken at time of hoof trimming reveals a strong association between the IQ motif-containing GTPase-activating protein 1 (IQGAP1) gene and sole hemorrhage in Holstein cattle
}

\author{
H. H. Swalve, ${ }^{, 1,2}$ C. Floren,$\dagger^{1}$ M. Wensch-Dorendorf, ${ }^{*}$ K. Schöpke, ${ }^{*}$ R. Pijl, $\ddagger$ K. Wimmers, $\S$ and B. Brenig \\ ${ }^{*}$ Institute of Agricultural and Nutritional Sciences, University of Halle, 06099 Halle, Germany \\ †Institute of Veterinary Medicine, University of Göttingen, Burckhardtweg 2, 37077 Göttingen, Germany \\ ¥Fischershäuser 1, 26441 Jever, Germany \\ §Research Unit of Molecular Biology, Leibniz Institute for Farm Animal Biology, Wilhelm-Stahl-Allee 2, 18196 Dummerstorf, Germany
}

\section{ABSTRACT}

Feet and leg problems have a major effect on the well-being and lifespan of the dairy cow and thus are economically important to the dairy farmer. Apart from approaches using genetic selection for classical traits from conformation scoring, attempts for genetic improvement can be based either on records of individual disease cases or on records of disorder status at time of hoof trimming. In this study, 1,962 firstlactation cows were subjected to hoof trimming with an assessment of disorder status for sole hemorrhage as a binary trait. Cows were from 7 large commercial herds in Mecklenburg-Western Pomerania (northeastern Germany) that had similar housing with cubicles, slatted flooring, little use of straw for bedding, and total mixed ration feeding. Cows were trimmed and assessed once, focusing on cows in the first half of the lactation. Herds were visited at intervals to enable recording of cohorts at a similar stage of lactation. Each cohort or herd-visit included between 31 and 165 cows. Additional measurements included body weight, back fat thickness, and body condition at time of trimming. Further data on dairy production, conformation scores, and reproductive performance were merged after collection of records had finished. The DNA extracted from blood of 1,183 cows was used for analysis with a custom-made array of 384 single nucleotide polymorphisms (SNP). The SNP were selected according to results from the literature for effects in classical conformation traits, from biochemical pathway analysis, and from comparative analysis of putative candidate genes in cattle, pigs, and sheep. Selection of cohorts of cows for SNP chip analysis was such that cohorts with extreme frequencies of disorders and cohorts with slightly deviating housing systems were excluded in this first step. The results

Received May 6, 2013.

Accepted September 16, 2013.

${ }^{1}$ These authors contributed equally to the work.

${ }^{2}$ Corresponding author: hermann.swalve@landw.uni-halle.de from a mixed threshold model analysis with genotype included as a fixed effect and accounting for relationships among animals revealed that the intronic SNP rs29017173 (A/G) within the IQ motif-containing GTPase-activating protein 1 (IQGAP1, Bos taurus autosome 21) was significantly associated with disorder status. Back-transformed means of disorder status for the 3 genotypes were $0.37(\mathrm{AA}), 0.52(\mathrm{AG})$, and $0.56(\mathrm{GG})$. Using the full data set of 1,962 cows, including the lesssuitable cohorts, gave back-transformed means of 0.51 (AA), 0.58 (AG), and 0.62 (GG). As SNP rs29017173 is included on the Illumina BovineSNP50 DNA Analysis BeadChip (Illumina Inc., San Diego, CA), a sample of 2,394 artificial insemination sires from the German calibration sample for genomic selection from birth years 1998 to 2003 was studied for possible correlated effects. The A/G polymorphism of SNP rs29017173 studied here was also associated with substantial effects for feet and leg traits from the classical conformation score system. Selection using this polymorphism will be facilitated by the fact that the same allele is favored for all traits with substantial effects.

Key words: hoof disorder, sole hemorrhage, association study, IQ motif-containing GTPase-activating protein $1(I Q G A P 1)$

\section{INTRODUCTION}

The relevance of diseases of the bovine hoof for the economy of dairy production and the welfare of the dairy cow is undisputed. Detailed economic calculations for the Netherlands have been reported by Bruijnis et al. (2010, 2013). Apart from management factors such as feeding, housing, and trimming of claws, genetic factors also contribute to the occurrence of bovine claw diseases as has been shown by, for example, van der Waaij et al. (2005), Koenig et al. (2005), Swalve et al. (2008), and van der Linde et al. (2010). Estimates of heritabilities for bovine claw diseases have been of low to moderate magnitude. This has also been demonstrated 
by very recent studies (Buch et al., 2011; Gernand et al., 2012; Neuenschwander et al., 2012; Pritchard et al., 2013). Obviously, conducting large field studies suitable for estimating genetic contributions to the incidence of bovine claw diseases has been hampered by the availability of records on those diseases. In Scandinavian countries, systems for the recording of diseases, including claw diseases, exist and the data have been used for genetic analyses (Laursen et al., 2009; Buch et al., 2011; Häggman et al., 2013). However, estimates of heritabilities, even considering the general level of heritability for health traits, have been on the low side because it is difficult to account for environmental effects in large sets of field data with a large number of persons responsible for recording. In producer-recorded data, the inherent problem appears to be that producers only report extreme cases of diseases (Zwald et al., 2004; Neuenschwander et al., 2012; Parker Gaddis et al., 2012). This problem can also be assumed for any data based on veterinary records (Laursen et al., 2009) as only severe cases are likely to be treated by veterinarians. An alternative approach is to use data recorded at time of herd hoof trimming, which has been suggested by van der Waaij et al. (2005), Koenig et al. (2005), and Swalve et al. (2005). Recording of disorders at time of herd trimming has the distinct advantage that complete contemporary groups; that is, healthy and nonhealthy cows, can be included in later analysis. Therefore, several newer studies (Ettema et al., 2007; Sogstad et al., 2007; Cramer et al., 2009; Kujala et al., 2010; Buch et al., 2011; Fjeldaas et al., 2011; Oberbauer et al., 2013) on environmental or genetic factors influencing bovine claw diseases have been conducted on records taken at time of trimming.

The relevance of direct observations on bovine claw health, in contrast to feet and leg conformation traits only, has been analyzed with selection index approaches (König and Swalve, 2006; van der Linde et al., 2010; Häggman et al., 2013) with the result that recording systems for claw diseases should be implemented. However, implementation of such systems will still be costly and may not even be feasible in some regions and countries. Genomic approaches could help to reduce costs as they could be based on parts of the population, thus resolving the need for nationwide recording systems. For classical conformation traits of feet and legs in dairy cows, several studies have been undertaken based on genome-scan approaches using microsatellites. Results for Danish data, also including direct observations on lameness and summarizing the relevant literature at that time, have been given by Buitenhuis et al. (2007). The authors reported 4 QTL for lameness as defined as an index of various claw diseases. Studies using high-density SNP data and phenotypes describing claw health so far are missing. Accordingly, the situation in dairy cattle is different from studies on feet and leg problems in pigs, where first results based on SNP data are available (Fan et al., 2009, 2011; Laenoi et al., 2011). In genomics, the use of SNP data on the DNA level is only one of several approaches. Regarding bovine laminitis, techniques to obtain tissue samples from the corium tissue of the bovine hoof have been established, and the expression of a sample of genes has been analyzed recently (Osorio et al., 2012). Thus, the establishment of such techniques could complement studies on the DNA level in the future.

In the present study, phenotypic observations for sole hemorrhage as an indicator for laminitis were used. Laminitis, also called pododermatitis aseptica diffusa, is a noninfectious disease caused by multiple factors (Vermunt and Greenough, 1994). One factor is a dietary carbohydrate overload that also leads to subacute ruminal acidosis (Nocek, 1997; Stone, 2004). Other factors that contribute to the incidence of the disease are problems of bedding and flooring (Nordlund et al., 2004). Although ruminal acidosis and laminitis can exist independently of each other, vasoactive substances can be produced in the gastrointestinal tract in the case of acidosis, and these substances may affect vascular perfusion of the digit (Lean et al., 2013). Laminitis can then manifest as damage to the vascular structures of the corium, the tissue layer between the horn structure and bone of the bovine hoof. In this study, the occurrence of hemorrhages was taken as an indicator of laminitis.

The objective of the present study was to examine relationships between genotypes for 384 preselected SNP and disorder status for sole hemorrhage based on the experiment as described in Schöpke et al. (2013). The experiment comprised records taken at time of trimming for 1,962 first-lactation Holstein cows from 7 large dairies in northeastern Germany that had comparable environments, including TMR feeding, cubicle housing, and slatted flooring.

\section{MATERIALS AND METHODS}

\section{Study Design and Data}

In designing the study, our specific aim was to collect records on the status of claw disorders at the time of hoof trimming in commercial herds that had similar housing conditions and feeding. Disorder status for sole hemorrhage as a binary trait was defined according to the existence of hemorrhages visible on the sole and included mild as well as more severe hemorrhages. Herds were selected from the pool of contract herds of the breed association Rinderzucht Mecklenburg-Vor- 
pommern. Selection from contract herds was desirable because these herds had been used for progeny testing and thus, around $50 \%$ of the sires were young bulls that were used in all contract herds. Selection of herds was according to conditions of housing and feeding such that large herds with cubicle housing, slatted flooring, and TMR feeding of a ration based on maize and grass silage were included. Cubicle housing, slatted floors, and TMR feeding can be viewed as standard conditions for larger herds in Germany. Further requirements were that only one unique system per farm was used and that sizeable groups of contemporaries would be available for the study. A contemporary group was defined as first-lactation cows being in a similar stage of lactation. Based on previous knowledge on the prevalence of laminitis in the course of lactation, as outlined in Pijl and Swalve (2006) and Swalve et al. (2011), recording at trimming focused on cows between d 50 and 150 of lactation. The recording consisted of visits to the specific herds by the recording team consisting of a veterinarian, a field technician, and a professional hoof trimmer. Around 30 to 60 cows were trimmed per day and farm. For larger contemporary groups, trimming per farm continued on consecutive days. In this way, contemporary groups were defined as herd visits $(\mathbf{H V})$ and therefore represented herd effects as well as time period effects.

The outline of the experiment is described in more detail in Schöpke et al. (2013). In brief, the present study included 1,962 first-lactation cows from 7 herds, that were visited several times each, which resulted in 24 herd visits. Cows were descendants of 274 sires. Average age of calving was $28.3 \pm 3.2$ mo. Approximately $62 \%$ of all trimmings occurred in the first $100 \mathrm{~d}$ of lactation and only $10 \%$ were conducted after d 200. Additional measurements at time of trimming included BW, back fat thickness via ultrasound scanner, height at sacrum, and BCS. Cows were trimmed once for the experiment such that all trimmings were the second trimming in the life of each cow. In all participating herds, it was standard practice to conduct a first trimming at the time of proven pregnancy of heifers; thus, trimmings in the experiment were the first trimming while lactating.

Table 1 displays the distribution of records per $\mathrm{HV}$, for herds $\mathrm{A}$ to $\mathrm{G}$ and visits 1 to 5 . The smallest contemporary group contained 31 records, the largest 165 records. Prevalence rate for sole hemorrhage was remarkably different between $\mathrm{HV}$, and on a high level on average. The general level of the prevalence rate is explained by 2 factors: (1) the inclusion of mild as well as more severe cases of hemorrhages, and (2) the focus on the first trimester of lactation for which the highest prevalence rates can be expected. For a genetic study and from a statistical point of view, the ideal situation would be a prevalence rate of around $50 \%$, which would result in an optimal distribution of prevalence across genetic lines or genotypes for specific genes. In general, this ideal situation was given for most of the HV. However, some HV, notably B_3, G_1, and G_3, exhibited an extreme prevalence of around $90 \%$. For a genetic study, prevalence rates within contemporary groups being close to zero or close to $100 \%$ are essentially noninformative because management effects statistically cannot be separated from genetic effects.

In our study, because of financial restrictions, only about half of the cows could be genotyped using a custom-made 384-SNP array. Hence, cows had to be selected for array genotyping, whereas the remaining cows and their records served as a sample for further analysis and validation. One obvious way of selecting a representative sample from a data set would be to sample cows at random. However, this way of sampling would reduce the size of the contemporary groups and hence counteract all efforts to make them as large as possible. Another way of selection in this situation would be to randomly select entire contemporary groups (i.e., HV). This in turn would not exclude the chance to select noninformative HV. Thus, entire HV were selected that exhibited a "normal" range of prevalence rates of between 0.25 and 0.71 . Following this strategy, cohorts $B \_1, G \_1$, and $G \_3$ were not considered for initial array genotyping. As the sample for array genotyping had to be reduced further, herd F and cohorts B_4 and E_2 were also excluded. In the case of herd $\mathrm{F}$, the argument for exclusion stemmed from the fact that rearing of young females had partly been on deep-straw bedding, whereas housing for cows was similar to that of all other herds. All other herds reared young stock on slatted floors. Exclusion of B_4 and E_2 and of some cows from C_1 and D_4 were random choices.

In summary, the assignment of cohorts and cows to a sample for array genotyping and a full sample comprising all observations resulted in a total of 1,962 cows in the full data set (data set I) and in 1,183 cows in data set II (array genotyping for 384 SNP). At time of trimming, data (i.e., claw disorder status, BW, BCS, height at sacrum, and back fat thickness) were collected electronically and stored in a personal digital assistant. Later, these data were merged with additional data provided by the computing center Vereinigte Informationssysteme Tierhaltung w.V. (Verden an der Aller, Germany). Additional data comprised linear conformation scores and conformation component traits ( 25 traits; $\mathrm{n}=1,685$ cows), first-lactation milk production ( 3 traits; $\mathrm{n}=1,956$ cows), and reproductive performance ( 5 traits; $\mathrm{n}=1,858$ cows). 
Table 1. Distribution of records across study cohorts (herd-visits at hoof trimming) and prevalence rates for sole hemorrhage for the entire set of observations (data set I) and the reduced set used for array genotyping (data set II)

\begin{tabular}{|c|c|c|c|c|c|c|}
\hline \multirow[b]{2}{*}{$\begin{array}{l}\text { Herd_- } \\
\text { Visit }\end{array}$} & \multicolumn{3}{|c|}{ Full data (data set I) } & \multicolumn{3}{|c|}{ Cows for array genotyping (data set II) } \\
\hline & No. & $\begin{array}{l}\text { Proportion of } \\
\text { data set I (\%) }\end{array}$ & $\begin{array}{l}\text { Prevalence } \\
\text { rate }\end{array}$ & No. & $\begin{array}{l}\text { Proportion of } \\
\text { data set II (\%) }\end{array}$ & $\begin{array}{l}\text { Prevalence } \\
\text { rate }\end{array}$ \\
\hline A_1 & 75 & 3.82 & 0.39 & 73 & 6.17 & 0.40 \\
\hline A_2 & 47 & 2.40 & 0.66 & 47 & 3.97 & 0.66 \\
\hline B_1 & 92 & 4.69 & 0.30 & 89 & 7.52 & 0.31 \\
\hline B_2 & 80 & 4.08 & 0.50 & 79 & 6.68 & 0.49 \\
\hline B_3 & 79 & 4.03 & 0.92 & & & \\
\hline B_4 & 69 & 3.52 & 0.71 & & & \\
\hline C_1 & 87 & 4.43 & 0.55 & 39 & 3.30 & 0.62 \\
\hline C_2 & 73 & 3.72 & 0.53 & 73 & 6.17 & 0.53 \\
\hline C_3 & 70 & 3.57 & 0.66 & 69 & 5.83 & 0.65 \\
\hline C_4 & 165 & 8.41 & 0.68 & 164 & 13.86 & 0.68 \\
\hline D_1 & 114 & 5.81 & 0.49 & 104 & 8.79 & 0.48 \\
\hline D_2 & 80 & 4.08 & 0.25 & 80 & 6.76 & 0.25 \\
\hline D_3 & 93 & 4.74 & 0.54 & 91 & 7.69 & 0.54 \\
\hline D_4 & 84 & 4.28 & 0.73 & 49 & 4.14 & 0.71 \\
\hline E_1 & 154 & 7.85 & 0.55 & 149 & 12.60 & 0.54 \\
\hline E_2 & 31 & 1.58 & 0.61 & & & \\
\hline F_1 & 40 & 2.04 & 0.43 & & & \\
\hline $\mathrm{F} \_2$ & 82 & 4.18 & 0.35 & & & \\
\hline F_3 & 70 & 3.57 & 0.43 & & & \\
\hline F_4 & 65 & 3.31 & 0.40 & & & \\
\hline F_5 & 82 & 4.18 & 0.70 & & & \\
\hline G_1 & 75 & 3.82 & 0.87 & & & \\
\hline G_2 & 80 & 4.08 & 0.59 & 77 & 6.51 & 0.58 \\
\hline G_3 & 75 & 3.82 & 0.89 & & & \\
\hline
\end{tabular}

Some of the SNP included in the array genotyping for $384 \mathrm{SNP}$ were also contained on the Illumina BovineSNP50 BeadChip (Illumina Inc., San Diego, CA). Given that virtually all Holstein AI bulls in use today have been genotyped, a further data set consisted of 2,394 AI Holstein sires of German ownership with genotyping results and information on EBV. All sires were born in years 1998 to 2003 and thus represented the core of the German calibration set for genomic selection as all had EBV with high repeatability for a total of $56 \mathrm{EBV}$ for individual traits as well as component traits and (sub)indices. This data set, denoted data set III, served as a basis for analysis of possible correlated effects in relation to effects based on data sets I and II. It should be noted, however, that the target trait of the present study, disorder status for sole hemorrhage, has not until now been routinely included in the German genetic evaluation system. Hence, it was not possible to use data set III as a validation sample. Data set III was provided by Vereinigte Informationssysteme Tierhaltung w.V.

\section{DNA Extraction, SNP Selection, and Genotyping}

Blood samples were taken at the time of trimming. Genomic DNA was extracted for all cows in data set I by using a modified protocol according to Miller et al. (1988). Quantification of DNA was then performed us- ing a NanoDrop ND-1000 spectrophotometer (Peqlab, Erlangen, Germany).

Selection of candidate gene SNP for a custom-made chip followed a 4-step-strategy that included compiling lists of published QTL; identifying syntenic chromosomal regions across cattle, pigs, and humans; selecting candidate genes; and selecting and validating SNP. First, an in silico analysis of published QTL associated with conformation traits in cattle (Supplementary Table S1; http://dx.doi.org/10.3168/jds.2013-6997) and pigs was performed. Published QTL studies in cattle have generally been based on genome scans using microsatellite markers and the granddaughter design in dairy cattle populations (Ashwell et al., 1998a,b, 2001, 2002; Boichard et al., 2003; Buitenhuis et al., 2007; Hiendleder et al., 2003; Schnabel et al., 2005; Schrooten et al., 2000). The individual traits included in the analyses were rear legs side view, rear legs rear view, rear legs set, hock quality, bone quality, quality of feet and legs, feet and leg score (composite index), foot diagonal, foot angle, hocks, heel depth, and lameness.

Because databases on synteny between cattle and pig are not publically available, we used the human genome as a reference to position the conformation trait QTL determined for cattle and pig, respectively. Only QTL regions that were overlapping on human chromosomes for both species were selected for further analysis. The linkage map locations of the bovine microsatellite 
markers used in the above-mentioned QTL studies were determined from published marker reports or from the US Department of Agriculture's Meat Animal Research Center website (http://www.marc.usda.gov/genome/ genome.html). Physical marker positions were determined on the Btau_4.0 genome assembly (National Center for Biotechnology Information, Bethesda, MD). Syntenic regions between cattle and humans were deciphered using BlastZ-net alignments (Kent et al., 2003; Schwartz et al., 2003). For each syntenic block, the exact position of the associated microsatellite marker was manually defined. Identified regions associated with the traits in question are given in Supplementary Table S2 (http://dx.doi.org/10.3168/jds.2013-6997).

Third, 74 functional and positional candidate genes were chosen from further studies on traits associated with locomotion and soundness of feet and legs in different livestock species. The Ingenuity Pathway Analysis software (Ingenuity Systems, Redwood City, CA) was used to identify 310 potentially functional candidate genes from approximately 4,800 annotated human genes within the selected regions to complete the 384-SNP chip. The syntenic regions contained between 2 and 568 genes. A list of 1,035 candidate genes was extracted. The genes were assigned to at least one of the following biological functions: development, function and disease of skeleton, muscles, and connective tissue $(\mathrm{n}=820)$; cell signaling $(\mathrm{n}=146)$; disorder in vitamin and mineral metabolism $(\mathrm{n}=487)$; or carbohydrate metabolism $(\mathrm{n}=33)$.

Finally, SNP conforming best to the following criteria were selected in the 384 genes: (a) validated SNP (according to NCBI or bovine 50K chip), (b) approximately 0.7- to 1-Mb interval between SNP, (c) minor allele frequency (MAF) of $>0.05$, (d) not located in a repeat region, and (e) tested on a Holstein-Friesian population. The SNP codes, locations, and frequencies were obtained from the National Center for Biotechnology Information (www.ncbi.nlm.nih.gov/SNP) or Illumina databases based on the Btau_4.0 genome assembly. The number of SNP was equal to the number of genes (1 SNP per gene). A summary of the SNP on the custommade chip is given in Table 2. For designing of custom genotyping bead chips, at least $60 \mathrm{bp}$ of sequence of either side of the SNP of interest were submitted to Illumina's online Assay Design Tool (ADT). Oligo pool assays and the Universal-32 BeadChip obtained from Illumina were used to perform GoldenGate genotyping assays of 1,183 cows according to manufacturer's protocols. Finally, the GoldenGate BeadChips were read on an IScan array scanner (Illumina Inc.) and analyzed using the GenomeStudio software (Illumina Inc.).

Because 1 SNP (HapMap54883-rs29017173, G/A) in IQGAP1 (GeneID: 532715) was strongly associated with sole hemorrhage as revealed by genotyping the cows in data set II (see Results and Discussion), all further samples $(\mathrm{n}=779)$ were genotyped for this SNP by a fluorescence resonance energy transfer assay (Förster, 1946). Primers were designed corresponding to the IQGAP1 genomic DNA sequence (NCBI; NW_003104533.1) using the Primer3 program (http:// frodo.wi.mit.edu/primer3/); probes were designed with Meltcalc (http://www.meltcalc.com). Primers and probes were synthesized by Sigma-Aldrich (Taufkirchen, Germany). A 143-bp fragment was amplified with the PCR primers BT_IQGAP1_SNP_F (5'-GAATCTGGCAGTCCAACAAA-3') and BT_IQGAP1_SNP_R (5'-AATCCCCAGCCCTTTATCTT-3'). The sensor probe BT_IQGAP1_Probe (5'-CCCCACTTAATCAGAACAGAAAT- $3^{\prime}$ ), labeled at the $5^{\prime}$ end with LightCycler red fluorophore LC610 and phosphorylated at the $3^{\prime}$ end, was designed to hybridize at the SNP site (polymorphic position is underlined). The anchor probe BT_IQGAP1_Anchor (5'-AGTACTGAGCTATGGAACACCTTGCC-3') was labeled with fluorescein at the $3^{\prime}$ end. The PCR reactions were performed in a LightCycler 480 instrument (Roche Diagnostics, Mannheim, Germany) and carried out with the following set-up: $40 \mathrm{ng}$ of DNA, $200 \mu \mathrm{mol}$ of each dNTP, $0.4 \mu \mathrm{mol}$ of each primer, $0.4 \mu \mathrm{mol}$ of hybridization probes (probe and anchor), and 1.5 U of Fast-Start Taq-polymerase in $1 \times$ buffer as recommended by the manufacturer (Roche Diagnostics) in a total reaction volume of 25 $\mu \mathrm{L}$. The PCR cycling program consisted of an initial denaturation step at $95^{\circ} \mathrm{C}$ for $10 \mathrm{~min}$, followed by 33 cycles of $30 \mathrm{~s}$ at $95^{\circ} \mathrm{C}, 30 \mathrm{~s}$ at $51^{\circ} \mathrm{C}$, and $30 \mathrm{~s}$ at $72^{\circ} \mathrm{C}$. After a denaturation step of $95^{\circ} \mathrm{C}$ for $30 \mathrm{~s}$, the melting curves were obtained from $40^{\circ} \mathrm{C}$ to $65^{\circ} \mathrm{C}$, with a temperature ramp rate of $0.11^{\circ} \mathrm{C} / \mathrm{s}$. The melting points are defined as maxima of the negative first derivative of the measured fluorescence over temperature. The melting temperature of the wild-type $(\mathrm{GG})$ was $58^{\circ} \mathrm{C}$ and for the SNP variant (AA) was $50^{\circ} \mathrm{C}$. Each fluorescence resonance energy transfer assay included animals representing the 3 genotypes as controls. If the aberrance of melting temperature of the samples and the controls was less than $0.5^{\circ} \mathrm{C}$, the results were accepted.

\section{Statistical Analyses}

Possible associations between disorder status for sole hemorrhage and SNP were tested applying the following methods. First, the genotypic association between individual SNP and binary disorder status was analyzed with a $\chi^{2}$ test as included in the FREQ procedure of the SAS package (SAS Institute Inc., Cary, NC). Second, the GLIMMIX procedure of SAS was used, employing a threshold model with fixed effects to account 
Table 2. Syntenic regions between cattle and pig and the number of selected and used SNP [minor allele frequency (MAF) $>0.05$ ]

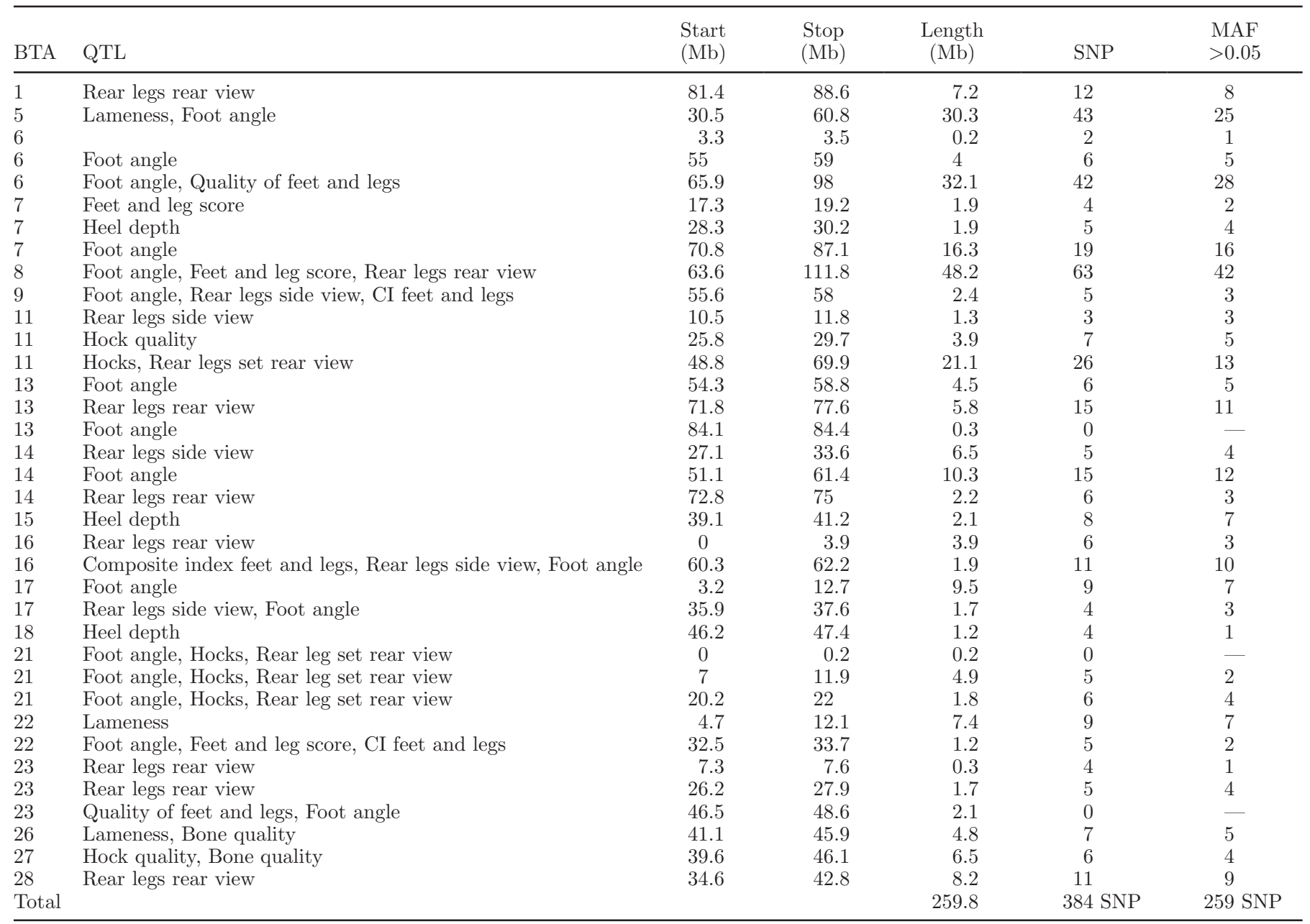

for environmental effects. All SAS procedures were run employing self-written macro language subprograms to enable easy repetitions for all SNP. In the GLIMMIX analyses, inclusion of fixed effects was based on the models as described by Schöpke et al. (2013) and defined as follows:

$$
\begin{gathered}
\operatorname{PR}_{\mathrm{LAM}}\left(\mathrm{y}_{\mathrm{ijkl}}=1\right)=\theta\left[\mu+\mathrm{GT}_{\mathrm{i}}+\mathrm{HV}_{\mathrm{j}}\right. \\
\left.+\mathrm{LS}_{\mathrm{k}}+\mathrm{b}_{1}(\mathrm{BW})+\mathrm{e}_{\mathrm{ijkl}}\right]
\end{gathered}
$$

where $\mathrm{PR}$ is the probability of occurrence of the disorder, $y_{\mathrm{ijk}}$ is the disorder score $(1=$ positive finding $), \theta$ is the probit link function, $\mu$ is the overall mean, $G_{\mathrm{i}}$ is the SNP genotype $(\mathrm{i}=1,2,3), \mathrm{HV}_{\mathrm{j}}$ is the fixed effect of herd-visit $(j=1, \ldots, 24$ for data set $I ; j=1$, ..., 14 for data set II), $\mathrm{LS}_{\mathrm{k}}$ is the fixed effect of stage of lactation as grouped into classes $(\mathrm{k}=1, \ldots, 5$ for DIM: $<50,50-99,100-149,150-149, \geq 150), \mathrm{b}_{1}(\mathrm{BW})$ is the regression coefficient for $\mathrm{BW}$, and $\mathrm{e}_{\mathrm{ijkl}}$ is the residual effect. The $P$-values for the genotype effect were subjected to the Bonferroni correction to account for multiple comparisons. Associations between genotype and disorder status were also tested using the PLINK software (Purcell et al., 2007). Results for individual SNP were compared using the allelic $\chi^{2}$ test. For all analyses with GLIMMIX and PLINK, 259 SNP with MAF $>0.05$ could be used.

A further analysis, run for all SNP in data set II and for 1 SNP genotype available for all cows in data set I, comprised a full mixed threshold model including relationships between animals applying the ASREML software (Gilmour et al., 2009). For this analysis, the model given above was augmented by a random animal effect.

\section{RESULTS AND DISCUSSION}

\section{Selection of SNP for the Custom-Made Chip}

The selection of SNP for the custom-made 384-SNP chip was based on the general assumption that sig- 
nificant genetic correlations between leg conformation traits and claw disorders exist as was shown by van der Waaij et al. (2005). The in silico analyses revealed 91 QTL associated with 12 feet and leg conformation traits as shown in Supplementary Table S1 (http://dx.doi. org/10.3168/jds.2013-6997). Identified QTL were spread across all bovine autosomes with the exception of BTA4, 10, and 20. Chromosomes BTA6, 9, 11-13, 15-17, 21-24, and 26-28 harbor QTL affecting 2 or 3 different traits. Before our study, no published QTL for laminitis or sole hemorrhage were available and, to our knowledge, this is still the case because there is no information on QTL for this disease in CattleQTLdb (www.animalgenome.org; last accession date: December 2012) or in PubMed.

For 51 of the 91 trait-associated bovine QTL, syntenic regions on human chromosomes HSA1-6, 8-12, 17-20, and 22 have been determined (Supplementary Table S2; http://dx.doi.org/10.3168/jds.2013-6997). Similar to the studies in cattle, QTL for conformation traits in pigs were also evaluated. Sixty-eight QTL in pigs were positioned on human chromosomes 1-11 and 13-17. Performing comparative genomics, 52 corresponding regions (Supplementary Table S3; http:// dx.doi.org/10.3168/jds.2013-6997) between cattle, pig, and human were identified on human chromosomes (HSA1-6, 8-12, 15, 19-20). Based on the bovine genome, the conserved syntenic regions were located on BTA1, 5-9, 11, 13-18, 21-23, and 26-28, covering an overall range of $259.8 \mathrm{Mb}$ (Table 2). The average QTL interval was 7.41 Mb and ranged from $0.2 \mathrm{Mb}$ (BTA21) to $48.2 \mathrm{Mb}$ (BTA8) on individual chromosomes.

A 4-step strategy was implemented to select 384 candidate genes with the purpose of designing a custom SNP chip with 1 SNP per candidate gene, but no SNP could be determined for the syntenic regions on BTA13 (84.1-84.4 Mb), BTA21 (0-0.2 Mb), or BTA23 (46.5-48.6 Mb; Table 2). The average physical distance between 2 neighboring SNP was $0.7 \mathrm{Mb}$, ranging from $8.9 \mathrm{~kb}$ to $17.8 \mathrm{Mb}$. In an initial in silico screen, $85 \%$ of the SNP were confirmed (GenCall score $\geq 0.6$ ). The $15 \%$ of failed markers (GenCall score <0.6) were replaced by alternative SNP that were located within the same genes. The genomic positions of the SNP based on Btau 4.1 can be summarized as follows: 39 coding SNP (10.2\%), two 5'-untranslated regions (UTR) upstream SNP (0.5\%), fourteen 3'-UTR downstream SNP (3.6\%), 278 intronic SNP (72.4\%), and 51 intergenic SNP (13.3\%). Because 125 SNP (32.5\%) had a MAF $<0.05$, only 259 SNP $(67.4 \%)$ were used for the association analysis with data set II and the Illumina GoldenGate Genotyping Assay. A list of all SNP included in this analysis is given in Supplementary File B (Excel; http://dx.doi.org/10.3168/jds.2013-6997).
A recently published genome-wide association analysis in US Holstein cows (Cole et al., 2011) identified various polymorphisms associated with 4 locomotion traits: foot angle (FA), rear legs side view (RLSV), rear legs rear view (RLR), and feet/legs score (FL). This confirmed our selection of genes even though different SNP within the genes had been chosen by Cole et al. (2011). Several of their top 100 most significant SNP effects (rounded cutoff for $P$-value: FA $P \geq 10^{-20}$, RLS $P \geq 10^{-15}$, RLR $P \geq 10^{-17}$, FL $P \geq 10^{-17}$ ) for each trait are located in or near $( \pm 5 \mathrm{Mb})$ our identified syntenic regions. Among the 20 most significant SNP effects, for FA 10 SNP (BTA14, 17, 18, 26), for RLSV 8 SNP (BTA1, 16, 18, 27), for RLR 4 SNP (BTA11, 26), and for FL 7 SNP (BTA5, 14, 26) were located in the same region or close to our studied bovine QTL regions. In a further genome-wide association analysis in pigs, applying the PorcineSNP60 BeadChip, candidate SNP and genes for several body conformation and feet and leg structure soundness traits have been identified (Fan et al., 2011). The genes GABRG2, AKAP2, ISOC1, ADAMTS19, MGMT, WISP2, WFDC5, and STK4 were also selected for our SNP chip compilation. Additionally, more than 25 of our selected genes represent the same gene families (i.e., transcription factors, collagen proteoglycans, transforming growth factor- $\beta$, calcium channels, fibroblast growth factors, and metalloproteases). Although the molecular background of bovine laminitis is largely unknown, an increasing number of studies have been conducted on the physiology and genetics of equine laminitis, indicating the relevance of metalloproteinases for this disease: $M M P-2$ and $M M P$ 9 are reported to be elevated during the acute phase of carbohydrate laminitis in horses (Johnson et al., 1998; Kyaw-Tanner and Pollitt, 2004; Kyaw-Tanner et al., 2008). A recent study (Visser and Pollitt, 2012) has, however, postulated that these proteases apparently do not initiate the pathogenesis of laminitis. Furthermore, the equine $A D A M T S$-4 was found to be upregulated in naturally occurring as well as in drug-induced laminitis (Budak et al., 2009; Coyne et al., 2009).

\section{Analysis of Experimental Data}

Analysis by PLINK of 259 SNP with MAF >0.05 using data set II revealed one highly significant association between disorder status for sole hemorrhage and the SNP (HapMap54883-rs29017173, A/G) in IQGAP1 (GeneID: 532715, BTA21). The $\chi^{2}$ value was 15.182 , and the $P$-value was 0.0000976 . The genotypic $\chi^{2}$ test in the FREQ procedure of SAS yielded a test statistic of 17.6813 with a $P$-value of 0.0001411 , equivalent to 0.0365 after Bonferroni correction. No other SNP showed significant associations after this correction. 
Table 3. Distribution of cows (absolute frequencies) for disorder status (0/1) for sole hemorrhage across genotypes for SNP (rs29017173)

\begin{tabular}{lccccccc}
\hline & \multicolumn{3}{c}{ Data set I } & & \multicolumn{3}{c}{ Data set II } \\
\cline { 2 - 4 } \cline { 6 - 8 } Genotype & 0 & 1 & Total & & 0 & 1 & Total \\
\hline AA & 197 & 208 & 405 & & 134 & 94 & 228 \\
AG & 429 & 579 & 1,008 & & 282 & 330 & 612 \\
GG & 209 & 335 & 544 & & 137 & 197 & 334 \\
Total & 835 & 1,122 & 1,957 & & 553 & 621 & 1,174 \\
\hline
\end{tabular}

After the remaining cows missing in data set II but available in the full data set I had been genotyped for SNP rs29017173, tests were repeated for this SNP. In total, 1,957 cows out of 1,962 cows with sufficient call rates for this SNP could be used. This resulted in $\chi^{2}$ values of 9.397 with a $P$-value of 0.00217313 from PLINK employing the allelic $\chi^{2}$ test, and a respective $\chi^{2}$ value of 9.9281 with a $P$-value of 0.007 from the genotypic $\chi^{2}$ test (Bonferroni correction not applicable). A summary of the distribution of disorder status across genotypes is given in Table 3 .

For both data sets, the frequency of the A allele of SNP rs29017173 was 0.46. Also, in both data sets, allelic frequencies were in equilibrium. Considering disorder status, distributions were shifted toward increased frequencies for $\mathrm{GG}$ and disorder status $=1$. In data set II (the array analysis), the GLIMMIX analysis applying a completely fixed model resulted in back-transformed means of the disorder status of 0.35 (AA), 0.49 (AG), and 0.54 (GG), thus equal to a reduction of 0.19 when comparing both homozygous genotypes. For the full data set, data set $I$, the corresponding values were 0.50 (AA), 0.56 (AG), and 0.60 (GG). Similar results were obtained from the mixed threshold model analysis when applying ASREML. Means back-transformed to the original scale from least square means of the ASREML analysis are given in Table 4. For the sake of comparison, the 2 left columns display the results when considering fixed effects, including the SNP effect, a random animal effect, and relationships between animals, whereas the 2 right columns show parameters as estimated from a model in which the effect of SNP rs29017173 was considered random instead of being treated as fixed. When $\sigma_{G}^{2}$ is the total additive genetic variance, $\sigma_{a}^{2}$ is the additive genetic (polygenic) variance, and $\sigma_{r s 2901173}^{2}$ represents the additive genetic variance associated with SNP rs29017173, $\sigma_{G}^{2}$ is defined as $\sigma_{a}^{2}+\sigma_{r s 29017173}^{2}$. From this, the proportion of the SNP variance relative to $\sigma_{G}^{2}$ was estimated as $15.3 \%$ (data set I) and $35.2 \%$ (data set II).

The effect of the allele substitution can be visualized when breeding values were estimated using the mixed threshold model, with the effect of SNP rs29017173 treated as fixed, as shown in Figure 1. As can be seen when inspecting back-transformed means (Table 4), the $\mathrm{G}$ allele exhibited a dominant nature. Animals with the AA genotype could be readily separated from the other 2 genotypes.

Genotypes in data set II $(\mathrm{n}=1,183$ cows; $\mathrm{n}=259$ $\mathrm{SNP}$, after exclusion of MAF <0.05) were also examined using GLIMMIX for a possible association with the supplementary traits recorded at time of trimming; that is, BW, BCS at time of trimming, and back fat thickness, as well as with other data available for this sample - linear conformation scores, conformation component traits, first-lactation milk production data, and reproductive performance. Fixed effects in the models used were adapted to the respective traits. As the target trait in this study was sole hemorrhage as an indicator for laminitis and the SNP chip was tailored toward the target trait, and as all "standard" traits in general are of lesser importance because they are already included in the estimation of genomic breeding values in many countries, the results of this part of our study will only be summarized briefly. Highly significant associations, after Bonferroni correction, were found for dairy character (genes ACVR1B, ITGA5, XPOT, all on BTA 5), for rump angle (genes SLC26a2, HMGXB3, both on BTA 7), for udder depth (genes $L P H N 3, I G F B P 7$, both on BTA 6), for rear teat placement (ITGA5, on BTA 5 ), and for BCS at time of classification (ADAMTS20, on BTA 5).

In data sets I and II, all 38 traits of the abovementioned trait groups were examined for possible associations with SNP rs29017173. No other trait except disorder status for sole hemorrhage showed a significant association.

\section{Testing Associations Using a Sample of Al Bulls}

Data set III, consisting of AI sires genotyped with the Illumina $54 \mathrm{~K}$ array and originating from birth years 1998 to 2003 ( $\mathrm{n}=2,394)$, served as a basis for analysis of possible effects of SNP rs29017173 on traits other than sole hemorrhage disorder. Numbers of sires per genotype were 630 (AA), 1,197 (AG), and 567 (GG). 


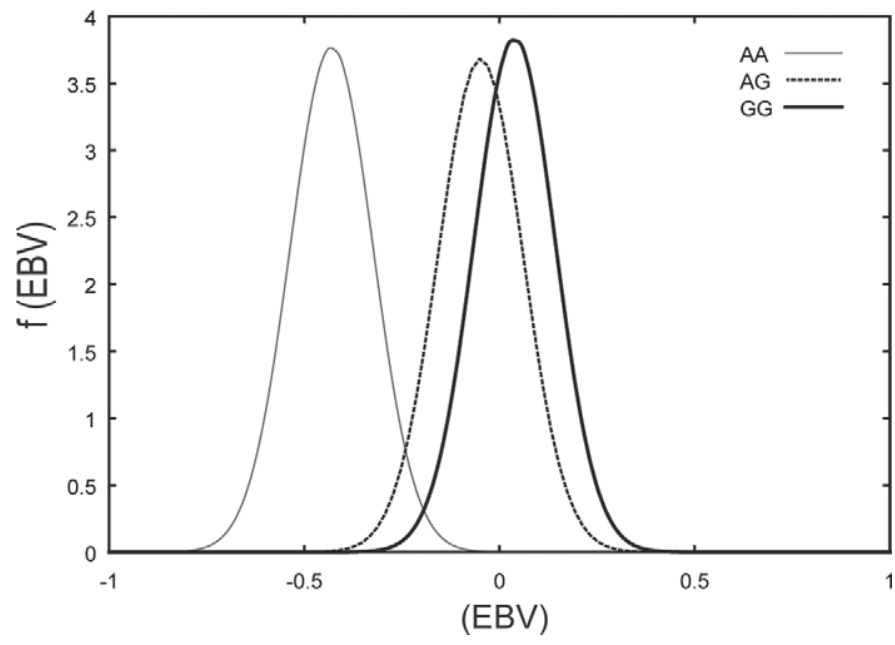

Figure 1. Density of EBV, f(EBV), assuming a normal distribution of EBV for disorder status of sole hemorrhage from a mixed threshold model analysis when treating SNP rs29017173 as fixed using data set II by genotype for SNP rs29017173.

Thus, the frequency of the A allele $[P(\mathrm{~A})]$ is 0.51 , slightly higher than in the cow population of data set I. As all sires had progeny proofs with high accuracies for a total of $56 \mathrm{EBV}$ of individual traits, component traits, and indices of trait groups, this sample of sires was highly suitable for this type of analysis. Results were obtained by applying a simple fixed model with genotype as the only fixed effect. Results for the most significant EBV and traits are shown in Table 5 and ordered by $F$-value of the genotype effect in the ANOVA. All EBV displayed in Table 5 exhibited $P$-values of $<0.0001$ for the effect of genotype. The EBV shown are not independent of each other because feet and legs total is an index from the respective subjectively scored or linearly scored trait. Rear legs rear view is included in the feet and legs index with a weight of 0.20 , equal to the 4 other feet and leg traits available.

In Germany, all traits in the genetic evaluation scheme are expressed on a scale with the mean of base animals equal to 100 and an SD of true breeding values of 12 . For traits with low heritability and comparatively little information, the SD of EBV can be considerably lower than the SD of the true breeding values. This is the case for temperament, whereas for feet and legs (total and index), the amount of information as well as the heritability is sufficient to reach a SD near the value for true breeding values. All sires had proofs for conformation with a reliability of $>60 \%$ and, for most of the sires, reliabilities were $>75 \%$. All associations are in favor of the A allele and are of substantial size compared with the SD (EBV) and relative to the fact that only half of the difference in the cow population can be estimated among sires. Slightly larger $P$-values, but again favoring the A-allele, were obtained for yield of fat and protein.

As no corrections or deregressions of sire proofs were applied for data set III, we hypothesized that the reli-

Table 4. Estimates of parameters from the mixed threshold model (ASREML analysis) when considering the genotype for SNP rs29017173 as fixed or random in data sets I (all cows) and II (cows included in SNP array analysis)

\begin{tabular}{|c|c|c|c|c|}
\hline \multirow[b]{3}{*}{ Estimated parameter $^{1}$} & \multicolumn{4}{|c|}{ Genotype (SNP rs29017173) in model as } \\
\hline & \multicolumn{2}{|c|}{ fixed } & \multicolumn{2}{|c|}{ random } \\
\hline & Data set I & Data set II & Data set I & Data set II \\
\hline$\sigma_{e}^{2}$ & 1 & 1 & 1 & 1 \\
\hline$\sigma_{a}^{2}$ & 0.0817923 & 0.107057 & 0.0793387 & 0.102769 \\
\hline$\sigma_{(r s 29017173)}^{2}$ & - & - & 0.014348 & 0.0557341 \\
\hline$\sigma_{P}^{2}$ & 1.0817923 & 1.107057 & 1.093687 & 1.1585031 \\
\hline$h^{2}$ & 0.0756 & 0.0967 & 0.0857 & 0.1368 \\
\hline$\sigma_{(r s 29017173)}^{2}\left(\%\right.$ of $\left.\sigma_{G}^{2}\right)$ & - & - & 15.31 & 35.16 \\
\hline$\sigma_{(r s 20017173)}^{2}\left(\%\right.$ of $\left.\sigma_{P}^{2}\right)$ & & & 1.32 & 8.88 \\
\hline $\begin{array}{l}P(\mathrm{y}=1 \mid \mathrm{AA})^{2} \\
P(\mathrm{y}=1 \mid \mathrm{AG})^{2}\end{array}$ & $\begin{array}{l}0.506^{\mathrm{a}} \\
0.578^{\mathrm{b} *}\end{array}$ & $\begin{array}{l}0.369^{\mathrm{a}} \\
0.519^{\mathrm{b} * * *}\end{array}$ & $\begin{array}{l}0.521^{\mathrm{a}} \\
0.576^{\mathrm{ab}}\end{array}$ & $\begin{array}{l}0.383^{\mathrm{a}} \\
0.516^{\mathrm{b} * * *}\end{array}$ \\
\hline$P(\mathrm{y}=1 \mid \mathrm{GG})^{2}$ & $0.615^{\mathrm{b} * *}$ & $0.559^{\mathrm{b} * * *}$ & $0.605^{\mathrm{b} * *}$ & $0.551^{\mathrm{b} * * *}$ \\
\hline Difference $\mathrm{P}(\mathrm{GG})-\mathrm{P}(\mathrm{AA})$ & $10.9^{* *}$ & $19.0^{* * *}$ & $8.4^{* *}$ & $16.8^{* * *}$ \\
\hline
\end{tabular}

$\overline{\mathrm{a}, \mathrm{b}}$ Different superscripts denote significant differences between back-transformed means.

${ }^{1}$ Where $\sigma_{e}^{2}=$ residual variance; $\sigma_{a}^{2}=$ additive genetic (polygenic) variance; $\sigma_{(r s 29017173)}^{2}=$ variance associated with SNP rs29017173; $\sigma_{P}^{2}=$ phenotypic variance; and $\sigma_{G}^{2}=$ additive genetic variance.

${ }^{2}$ Probability of disorder status $=1$ (back-transformed mean of disorder status on the original scale).

${ }^{*} P<0.05 ;{ }^{* *} P<0.01$; *** $P<0.001$. 
Table 5. Least square means of SNP rs29017173 genotypes for the 6 most significant trait associations.

\begin{tabular}{|c|c|c|c|c|c|c|c|c|}
\hline \multirow[b]{3}{*}{$\mathrm{EBV}^{1}$} & \multirow[b]{3}{*}{$\begin{array}{l}\text { SD (EBV) } \\
\text { (all sires) }\end{array}$} & \multirow[b]{3}{*}{$F$-value ${ }^{2}$} & \multicolumn{6}{|c|}{ SNP rs29017173 genotype } \\
\hline & & & \multicolumn{2}{|c|}{$\mathrm{AA}$} & \multicolumn{2}{|c|}{$\mathrm{AG}$} & \multicolumn{2}{|c|}{ GG } \\
\hline & & & LSM & $\mathrm{SE}$ & LSM & $\mathrm{SE}$ & LSM & $\mathrm{SE}$ \\
\hline Feet and legs total ${ }^{3}$ & 10.2 & 11.49 & 100.49 & 0.40 & 100.07 & 0.29 & 97.91 & 0.43 \\
\hline Feet and legs score ${ }^{4}$ & 7.8 & 11.29 & 100.41 & 0.31 & 99.99 & 0.22 & 98.40 & 0.33 \\
\hline Body depth & 9.3 & 10.95 & 100.89 & 0.37 & 99.61 & 0.27 & 98.39 & 0.39 \\
\hline Rear legs rear view & 8.0 & 10.41 & 100.55 & 0.32 & 100.05 & 0.23 & 98.54 & 0.34 \\
\hline
\end{tabular}

${ }^{1}$ Traits are EBV for AI sires ( $\mathrm{n}=2,371$ for temperament, $\mathrm{n}=2,394$ for all other traits).

${ }^{2}$ All $P$-values $<0.0001$.

${ }^{3}$ Feet and legs total $=0.5$ (Feet and legs score) +0.5 (Feet and legs index).

${ }^{4}$ Feet and legs score was subjectively scored.

${ }^{5}$ Feet and legs index = index from all feet and legs traits as scored linearly.

ability of EBV could influence the magnitude of the contrast when comparing the 2 homozygous genotypes. Setting higher requirements on the reliability of EBV for feet and legs total resulted in increasing magnitudes for the contrast. The entire data set III showed a contrast of 2.58 (see Table 5), requiring $78 \%$ gave 2.93 (n $=2,247$ sires) and limiting the analysis to sires with $>81 \%$ reliability resulted in a difference between the 2 homozygous genotypes of 3.1 ( $\mathrm{n}=1,779$ sires). Higher requirements more than halved the size of the data set and thus were considered impractical.

Based on the results for SNP rs29017173 from the cow data (data sets I and II), it can be hypothesized for the feet and leg conformation traits that cows receive higher scores when they are able to move in a "healthy" way. Without any speculation and given the results from all data sets, no harmful side effects would result from selection favoring the A allele.

Figure 2 shows the frequency distribution of EBV for feet and legs total by genotype. What is visualized when comparing homozygous genotypes is a decrease of the number of AA sires for low EBV and an even larger increase of the number of AA sires for high EBV.

\section{IQGAP1 as a Candidate Gene}

Based on the results from this study, IQGAP1 is a promising candidate gene for the pathogenesis of sole hemorrhage in cattle. The associated SNP rs29017173 is located in intron 15 of the IQGAP1 gene on BTA21 at position 22,562,920 (UMD_3.1). The SNP was selected for the chip because it met all criteria described in the Materials and Methods section: it fulfilled the criterion of a $0.5-\mathrm{Mb}$ interval between the adjacent SNP and it has been validated in a Holstein-Friesian population with allele frequency of $\mathrm{A}=0.6$ and $\mathrm{G}=$
0.4 , and genotype frequency of $\mathrm{AG}=0.4, \mathrm{AA}=0.4$, and $\mathrm{GG}=0.2$ (http://www.ncbi.nlm.nih.gov/projects/ SNP/snp_ss.cgi?subsnp_id $=38333464)$.

The IQGAP1 gene codes for a ubiquitously expressed scaffolding protein that contains several proteininteracting domains (White et al., 2009). It binds to a variety of targets and modulates fundamental cellular activities, including cytoskeletal architecture, cell-cell adhesion, transcription, and diverse signaling pathways (Ren et al., 2007). Urao et al. (2010) demonstrated a critical role of IQGAP1 in postischemic neovascularization and tissue repair by regulating endothelial cell-mediated angiogenesis and reactive oxygen species production in ischemic tissues and inflammatory cell infiltration. Moreover, IQGAP1-/ - mice show reduced capillary density, limb blood recovery, and $\alpha$-actin positive arterioles. In mice lacking $I Q G A P 1$ and subjected to a femoral artery ligation, tissue damage increased, characterized by nail bed degeneration, toe edema, and, to a certain degree, necrosis. Based on these reports, it is conceivable that IQGAP1 could be causative for the development of sole hemorrhage in cattle or be critically involved in the repair of damaged vascular tissue. The role of IQGAP1 as a gene interacting with vascular endothelial growth factors has also been pointed out by Kowanetz and Ferrara (2006).

In another respect, IQGAP1 could be viewed as a candidate gene: Gao et al. (2011) identified IQGAP1 as a key regulator of dendritic spine number with a specific role in cognitive but not emotional or motivational processes. In a series of experiments with wildtype mice and IQGAP1 knockout mice, these authors were able to show the impaired behavior of mice with respect to context-dependent fear conditioning, tonedependent fear conditioning, freezing to context after a shock, and object discrimination. Thus, these findings 


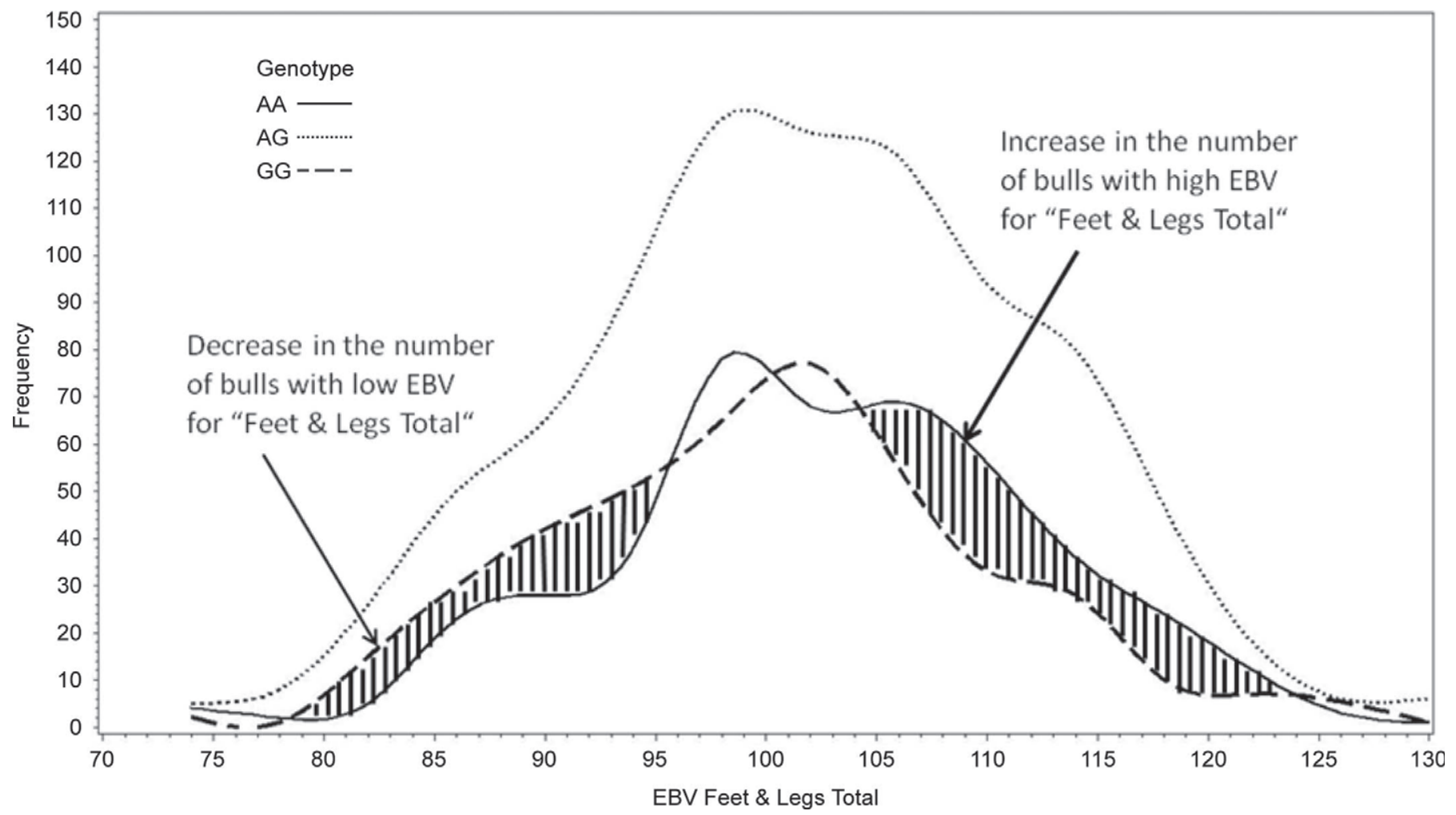

Figure 2. Distribution of EBV for Feet and Legs Total of AI bulls from the official national evaluation (data set III, $\mathrm{n}=2,394)$ by genotype for SNP rs29017173.

indicate the need to further explore the behavior of cows of different IQGAP1 genotypes, as indications on behavioral aspects are given by our results from sire EBV for temperament in data set III.

\section{General Aspects}

Health traits in general are often characterized by low degrees of heritability and very dominant environmental effects. This is partly due to the difficulty of precisely defining "healthy" or "diseased" states; that is, phenotyping for health appears to be very difficult. Furthermore, the large dependency on environmental factors gives rise to the occurrence of genotype by environmental interaction. With respect to health status, genotypes may differ in one environment but not in another. The aforementioned principles were the basis of the planning of this study. For phenotyping of cows, we attempted to standardize the environment to the most common one in Germany: slatted flooring, little use of straw, feeding a TMR, and hoof trimming in the first half of the first lactation. Additional efforts toward standardization consisted of visiting a few large herds $(\mathrm{n}=7)$ only and having all trimming work and health status appraisal done by only one person. Because of financial restrictions, only $60 \%$ of all samples could be used for genotyping with the custom-made 384-SNP array. Hence, parts of the samples had to be selected. First, herd-visit cohorts with extreme frequencies for the disorder were excluded. Second, one herd in which the rearing of animals differed from the system in other herds was excluded. Obviously, these choices had to be made before genotyping started. After inspection of the results for both the reduced and the full data sets, our expectations were confirmed: cohorts with extreme disease frequencies or deviant environmental systems can greatly influence the results. However, the association between the IQGAP1 gene and the prevalence of mild as well as more severe cases of hemorrhage as an indicator for laminitis is still detectable, even when less suitable data are analyzed.

\section{CONCLUSIONS}

Diseases and disorders of the hoof are important factors influencing the well-being and milk production of the dairy cow. In this study, the IQGAP1 gene on BTA21 was identified, for which indications of its major role in the etiology and course of sole hemorrhage are overwhelming. Polymorphism of the intronic SNP 
used here was associated with substantial effects when considering sole hemorrhage but also with effects for feet and leg traits from the classical conformation score system. Fortunately, selection using this polymorphism will be facilitated by the fact that the same allele is favored for all traits with substantial effects. This study demonstrates the difficulties encountered when trying to separate genetic effects or individual gene effects from environmental factors in studies of disease. Even when a substantial genetic background exists, the etiology of a disease is highly dependent on the environment, and genetic factors may not be detectable in some environments but are readily separated in other environments.

\section{ACKNOWLEDGMENTS}

The authors acknowledge the financial support from the German Federal Ministry of Education and Research under the FUGATO-plus program through the grant GENE-FL. The support and interest of the participating dairy farms and the cattle breeding organization RMV (Rinderzucht Mecklenburg-Vorpommern $\mathrm{GmbH}$, Woldegk, Germany) is gratefully acknowledged. The authors thank F. Rosner and S. Weidling (University of Halle, Germany) for their technical assistance with data collection in the field. The expert technical assistance of I. Wiedemann and S. Pach (University of Goettingen, Germany) as well as H. Tychsen (Leibniz Institute for Farm Animal Biology, Dummerstorf, Germany) is highly appreciated. Diana Sorg (University of Halle) is thanked for help in preparing the manuscript.

\section{REFERENCES}

Ashwell, M. S., Y. Da, C. P. Van Tassell, P. M. Vanraden, R. H. Miller, and C. E. Rexroad Jr. 1998a. Detection of putative loci affecting milk production and composition, health, and type traits in a United States Holstein population. J. Dairy Sci. 81:3309-3314.

Ashwell, M. S., Y. Da, P. M. VanRaden, C. E. Rexroad Jr., and R. H. Miller. 1998b. Detection of putative loci affecting conformational type traits in an elite population of United States Holsteins using microsatellite markers. J. Dairy Sci. 81:1120-1125.

Ashwell, M. S., D. W. Heyen, J. I. Weller, M. Ron, T. S. Sonstegard, C. P. Van Tassell, and H. A. Lewin. 2005. Detection of quantitative trait loci influencing conformation traits and calving ease in Holstein-Friesian cattle. J. Dairy Sci. 88:4111-4119.

Ashwell, M. S., C. P. Van Tassell, and T. S. Sonstegard. 2001. A genome scan to identify quantitative trait loci affecting economically important traits in a US Holstein population. J. Dairy Sci. 84:2535-2542.

Boichard, D., C. Grohs, F. Bourgeois, F. Cerqueira, R. Faugeras, A. Neau, R. Rupp, Y. Amigues, M. Y. Boscher, and H. Leveziel. 2003. Detection of genes influencing economic traits in three French dairy cattle breeds. Genet. Sel. Evol. 35:77-101.

Bruijnis, M. R. N., H. Hogeveen, and E. N. Stassen. 2010. Assessing economic consequences of foot disorders in dairy cattle using a dynamic stochastic simulation model. J. Dairy Sci. 93:2419-2432.

Bruijnis, M. R. N., H. Hoogeveen, and E. N. Stassen. 2013. Measures to improve dairy cow foot health: Consequences for farmer in- come and dairy cow welfare. Animal 7:167-175. http://dx.doi org $/ 10.1017 /$ S1751731112001383.

Buch, L. H., A. C. Sørensen, J. Lassen, P. Berg, J.-Å. Eriksson, J. H. Jakobsen, and M. K. Sørensen. 2011. Hygiene-related and feedrelated hoof diseases show different patterns of genetic correlations to clinical mastitis and female fertility. J. Dairy Sci. 94:15401551. http://dx.doi.org/10.3168/jds.2010-3137.

Budak, M. T., J. A. Orsini, C. C. Pollitt, and N. A. Rubinstein. 2009. Gene expression in the lamellar dermis-epidermis during the developmental phase of carbohydrate overload-induced laminitis in the horse. Vet. Immunol. Immunopathol. 131:86-96.

Buitenhuis, A. J., M. S. Lund, J. R. Thomasen, B. Thomsen, V. Hunnicke Nielsen, C. Bendixen, and B. Guldbrandtsen. 2007. Detection of quantitative trait loci affecting lameness and leg conformation traits in Danish Holstein cattle. J. Dairy Sci. 90:472-481.

Cole, J. B., G. R. Wiggans, L. Ma, T. S. Sonstegard, T. J. Lawlor Jr., B. A. Crooker, C. P. Van Tassell, J. Yang, S. Wang, L. K. Matukumalli, and Y. Da. 2011. Genome-wide association analysis of thirty one production, health, reproduction and body conformation traits in contemporary U.S. Holstein cows. BMC Genomics 12:408.

Coyne, M. J., H. Cousin, J. P. Loftus, P. J. Johnson, J. K. Belknap C. M. Gradil, S. J. Black, and D. Alfandari. 2009. Cloning and expression of ADAM-related metalloproteases in equine laminitis. Vet. Immunol. Immunopathol. 129:231-241.

Cramer, G., K. D. Lissemore, C. L. Guard, K. E. Leslie, and D. F. Kelton. 2009. Herd-level risk factors for seven different foot lesions in Ontario Holstein cattle housed in tie stalls or free stalls. J. Dairy Sci. 92:1404-1411. http://dx.doi.org/10.3168/jds.2008-1134.

Ettema, J. F., N. Capion, and A. E. Hill. 2007. The association of hoof lesions at claw trimming with test-day milk yield in Danish Holsteins. Prev. Vet. Med. 79:224-243.

Fan, B., S. K. Onteru, Z. Q. Du, D. J. Garrick, K. J. Stalder, and M. F. Rothschild. 2011. Genome-wide association study identifies loci for body composition and structural soundness traits in pigs. PLoS ONE 6:e14726.

Fan, B., S. K. Onteru, B. E. Mote, T. Serenius, K. J. Stalder, and M. F. Rothschild. 2009. Large-scale association study for structural soundness and leg locomotion traits in the pig. Genet. Sel. Evol. $41: 14$.

Fjeldaas, T., A. M. Sogstad, and O. Østerås. 2011. Locomotion and claw disorders in Norwegian dairy cows housed in freestalls with slatted concrete, solid concrete, or solid rubber flooring in the alleys. J. Dairy Sci. 94:1243-1255. http://dx.doi.org/10.3168/ jds.2010-3173.

Förster, T. 1946. Energiewanderung und Fluoreszenz. Naturwissenschaften 33:166-175.

Gao, C., S. F. Frausto, A. L. Guedea, N. C. Tronson, V. Jovasevic, K. Leaderbrand, K. A. Corcoran, Y. F. Guzmán, G. T. Swanson, and J. Radulovic. 2011. IQGAP1 regulates NR2A signaling, spine density, and cognitive processes. J. Neurosci. 31:8533-8542. http:// dx.doi.org/10.1523/JNEUROSCI.1300-11.2011.

Gernand, E., P. Rehbein, U. v. Borstel, and S. König. 2012. Incidences of and genetic parameters for mastitis, claw disorders and common health traits recorded in dairy cattle contract herds. J. Dairy Sci. 95:2144-2156. http://dx.doi.org/10.3168/jds.2011-4812.

Gilmour, A. R., B. J. Gogel, B. R. Cullis, and R. Thompson. 2009. ASREML User Guide. VSN International Ltd., Hemel Hempstead, UK.

Häggman, J., J. Juga, M. J. Sillanpää, and R. Thompson. 2013. Genetic parameters for claw health and feet and leg conformation traits in Finnish Ayrshire cows. J. Anim. Breed. Genet. 130:8997. http://dx.doi.org/10.1111/j.1439-0388.2012.01007.x.

Hiendleder, S., H. Thomsen, N. Reinsch, J. Bennewitz, B. Leyhe-Horn, C. Looft, N. Xu, I. Medjugorac, I. Russ, C. Kuhn, G. A. Brockmann, J. Blumel, B. Brenig, F. Reinhardt, R. Reents, G. Averdunk, M. Schwerin, M. Forster, E. Kalm, and G. Erhardt. 2003. Mapping of QTL for body conformation and behavior in cattle. J. Hered. 94:496-506.

Johnson, P. J., S. C. Tyagi, L. C. Katwa, V. K. Ganjam, L. A. Moore, J. M. Kreeger, and N. T. Messer. 1998. Activation of extracel- 
lular matrix metalloproteinases in equine laminitis. Vet. Rec. 142:392-396.

Kent, W. J., R. Baertsch, A. Hinrichs, W. Miller, and D. Haussler. 2003. Evolution's cauldron: Duplication, deletion, and rearrangement in the mouse and human genomes. Proc. Natl. Acad. Sci. USA 100:11484-11489.

Koenig, S., A. R. Sharifi, H. Wentrot, D. Landmann, M. Eise, and H. Simianer. 2005. Genetic parameters of claw and foot disorders estimated with logistic models. J. Dairy Sci. 88:3316-3325.

König, S., and H. H. Swalve. 2006. A model calculation on the prospects of an improvement of claw health in dairy cattle via genetic selection. Zuchtungskunde 78:345-356.

Kowanetz, M., and N. Ferrara. 2006. Vascular endothelial growth factor signaling pathways: Therapeutic perspective. Clin. Cancer Res. 12:5018-5022. http://dx.doi.org/10.1158/1078-0432.CCR06-1520.

Kujala, M., I. R. Dohoo, and T. Soveri. 2010. White-line disease and haemorrhages in hooves of Finnish dairy cattle. Prev. Vet. Med. 94:18-27.

Kyaw-Tanner, M., and C. C. Pollitt. 2004. Equine laminitis: Increased transcription of matrix metalloproteinase-2 (MMP-2) occurs during the developmental phase. Equine Vet. J. 36:221-225.

Kyaw-Tanner, M. T., O. Wattle, A. W. van Eps, and C. C. Pollitt. 2008. Equine laminitis: Membrane type matrix metalloproteinase-1 (MMP-14) is involved in acute phase onset. Equine Vet. J. 40:482-487.

Laenoi, W., M. J. Uddin, M. U. Cinar, C. Große-Brinkhaus, D. Tesfaye, E. Jonas, A. M. Scholz, E. Tholen, C. Looft, K. Wimmers, C. Phatsara, H. Juengst, H. Sauerwein, M. Mielenz, and K. Schellander. 2011. Quantitative trait loci analysis for leg weakness related traits in a Duroc $\times$ Pietrain crossbred population. Genet. Sel. Evol. 43:13. http://dx.doi.org/10.1186/1297-9686-43-13.

Laursen, M. V., D. Boelling, and T. Mark. 2009. Genetic parameters for claw and leg health, foot and leg conformation, and locomotion in Danish Holsteins. J. Dairy Sci. 92:1770-1777. http://dx.doi. org/10.3168/jds.2008-1388.

Lean, I. J., C. T. Westwood, H. M. Golder, and J. J. Vermunt. 2013. Impact of nutrition on lameness and claw health in cattle. Livest. Sci. 156:71-87. http://dx.doi.org/10.1016/j.livsci.2013.06.006.

Miller, S. A., D. D. Dykes, and H. F. Polesky. 1988. A simple salting out procedure for extracting DNA from human nucleated cells. Nucleic Acids Res. 16:1215.

Neuenschwander, T. F.-O., F. Miglior, J. Jamrozik, O. Berke, D. F. Kelton, and L. R. Schaeffer. 2012. Genetic parameters for producer-recorded health data in Canadian Holstein cattle. Animal 6:571-578.

Nocek, J. E. 1997. Bovine acidosis: Implications on laminitis. J. Dairy Sci. 80:1005-1028.

Nordlund, K. V., N. B. Cook, and G. R. Oetzel. 2004. Investigation strategies for laminitis problem herds. J. Dairy Sci. 87(E. Suppl.):E27-E35.

Oberbauer, A. M., S. L. Berry, J. M. Belanger, R. M. McGoldrick, J. M. Pinos-Rodriquez, and T. R. Famula. 2013. Determining the heritable component of dairy cattle foot lesions. J. Dairy Sci. 96:605-613. http://dx.doi.org/10.3168/jds.2012-5485.

Osorio, J. S., B. C. Fraser, D. E. Graugnard, S. S. Singh, J. K. Drackley, E. F. Garret, and J. J. Loor. 2012. Corium tissue expression of genes associated with inflammation, oxidative stress, and keratin formation in relation to lameness in dairy cows. J. Dairy Sci. 95:6388-6396. http://dx.doi.org/10.3168/jds.2011-5143.

Parker Gaddis, K. L., J. B. Cole, J. S. Clay, and C. Maltecca. 2012. Incidence validation and relationship analysis of producer-recorded health event data from on-farm computer systems in the United States. J. Dairy Sci. 95:5422-5435. http://dx.doi.org/10.3168/ jds.2012-5572.

Pijl, R., and H. H. Swalve. 2006. An analysis of claw disorders diagnosed at claw trimming. Pages 34-36 in Proc. 14th Symp. 6th Conf. Lameness in Ruminants, Uruguay. http://www.ivis.org/proceedings/rumlameness/toc.asp.

Pritchard, T., M. Coffey, R. Mrode, and E. Wall. 2013. Genetic parameters for production, health, fertility and longevity traits in dairy cows. Animal 7:34-46. http://dx.doi.org/10.1017/ S1751731112001401.

Purcell, S., B. Neale, K. Todd-Brown, L. Thomas, M. A. R. Ferreira, D. Bender, J. Maller, P. Sklar, P. I. W. de Bakker, M. J. Daly, and P. C. Sham. 2007. PLINK: A toolset for whole-genome association and population-based linkage analysis. Am. J. Hum. Genet. $81: 559-575$.

Ren, J. G., Z. Li, and D. B. Sacks. 2007. IQGAP1 modulates activation of B-Raf. Proc. Natl. Acad. Sci. USA 104:10465-10469.

Schnabel, R. D., T. S. Sonstegard, J. F. Taylor, and M. S. Ashwell. 2005. Whole-genome scan to detect QTL for milk production, conformation, fertility and functional traits in two US Holstein families. Anim. Genet. 36:408-416.

Schöpke, K., S. Weidling, R. Pijl, and H. H. Swalve. 2013. Relationships between bovine hoof disorders, body condition traits, and test-day yields. J. Dairy Sci. 96:679-689. http://dx.doi. org/10.3168/jds.2012-5728.

Schrooten, C., H. Bovenhuis, W. Coppieters, and J. A. Van Arendonk. 2000. Whole genome scan to detect quantitative trait loci for conformation and functional traits in dairy cattle. J. Dairy Sci. 83:795-806.

Schwartz, S., W. J. Kent, A. Smit, Z. Zhang, R. Baertsch, R. C. Hardison, D. Haussler, and W. Miller. 2003. Human-mouse alignments with BLASTZ. Genome Res. 13:103-107.

Sogstad, A. M., O. Østerås, T. Fjeldaas, and A. O. Refsdal. 2007. Bovine claw and limb disorders at claw trimming related to milk yield. J. Dairy Sci. 90:749-759.

Stone, W.C. 2004. Nutritional approaches to minimize subacute ruminal acidosis and laminitis in dairy cattle. J. Dairy Sci. 87(E. Suppl.):E13-E26.

Swalve, H. H., H. Alkhoder, and R. Pijl. 2008. Estimates of breeding values for sires based on diagnoses recorded at hoof trimming: Relationships with EBV for conformation traits. Interbull Bull. 38:87-90.

Swalve, H. H., H. Alkhoder, and R. Pijl. 2011: Genetic background of disorders of the bovine hoof from data collected at hoof trimming. 16th Symposium and 8th Conference on Lameness in Ruminants, Rotorua, New Zealand. http://www.ivis.org/proceedings/ rumlameness/toc.asp.

Swalve, H. H., R. Pijl, M. Bethge, F. Rosner, and M. Wensch-Dorendorf. 2005. Analysis of genetic and environmental effects on claw disorders diagnosed at hoof trimming. Page 29 in Book of Abstracts for 56th Annual Meeting of the EAAP, Uppsala, Sweden. EAAP, Rome, Italy.

Urao, N., M. Razvi, J. Oshikawa, R. D. McKinney, R. Chavda, W. F. Bahou, T. Fukai, and M. Ushio-Fukai. 2010. IQGAP1 is involved in post-ischemic neovascularization by regulating angiogenesis and macrophage infiltration. PLoS ONE 5:e13440. http://dx.doi. org/10.1371/journal.pone.0013440.

van der Linde, C., G. de Jong, E. P. C. Koenen, and H. Eding. 2010. Claw health index for Dutch dairy cattle based on claw trimming and conformation data. J. Dairy Sci. 93:4883-4891.

van der Waaij, E. H., M. Holzhauer, E. Ellen, C. Kamphuis, and G. de Jong. 2005. Genetic parameters for claw disorders in Dutch dairy cattle and correlations with conformation traits. J. Dairy Sci. 88:3672-3678.

Vermunt, J. J., and P. R. Greenough. 1994. Review: Predisposing factors of laminitis in cattle. Br. Vet. J. 150:151-164.

Visser, M. B., and C. C. Pollitt. 2012. The timeline of metalloprotease events during oligofructose induced equine laminitis development. Equine Vet. J. 44:88-93.

White, C. D., M. D. Brown, and D. B. Sacks. 2009. IQGAPs in cancer: A family of scaffold proteins underlying tumorigenesis. FEBS Lett. 583:1817-1824.

Zwald, N. R., K. A. Weigel, Y. M. Chang, R. D. Welper, and J. S. Clay. 2004. Genetic selection for health traits using producerrecorded data. I. Incidence rates, heritability estimates and sire breeding values. J. Dairy Sci. 87:4287-4294. 